\title{
A Rare Case of Childhood Lipoblastoma presenting as Tongue Mass
}

https://doi.org/10.47210/bjohns.2021.v29i1.403

\section{Anand $V^{1}$ Aishwarya Anand, ${ }^{1}$ Manaswini Ramachandra, ${ }^{2}$ Sridurga Janarthanan ${ }^{1}$}

\section{Introduction}

\section{ABSTRACT}

Lipoblastoma is a rare benign tumour arising from embryonic white fat been commonly noted in limbs and trunk, but tongue involvement is rare and has not yet been reported.

Case Report

A child with tongue lipoblastoma is reported, whose imaging reported an encapsulated, well-delineated, fat-containing tumour. Surgical excision was performed with no post-operative morbidities.

\section{Discussion}

Lipoblastoma is an uncommon childhood tumour, which rarely affects the tongue. It presents as a progressive painless swelling, rarely causing any symptom. MRI is helpful to assess the precise location and extent of the lesion. Although the ratio of fat to myxocollagenous tissue in the tumour is variable, the diagnosis can be suggested in most cases based on the imaging characteristics. Recommended treatment is complete surgical excision and confirmation of diagnosis by histopathological examination.

$\underline{\text { Kevwords }}$

Lipoblastoma; Child; Tongue

$\mathrm{T}$ he most commonly encountereded paediatric soft tissue tumour in the head and neck region is haemangioma. Lipoblastomas, though rare, should be kept in mind in cases of such presentation. Of these, a clinical diagnosis of lipoblastoma can be made taking into consideration the age of patient and clinical examination first, followed by a probable confirmation with MRI \pm CT scan.

\section{Case Report}

A 4 year old boy, reported to the otorhinolaryngology outpatient department, with the complaints of painless swelling in the tongue for 45 days. The swelling gradually increased in the size to attain the present size. Lesion did not cause any other symptoms.

On examination of tongue, a smooth, firm, nontender swelling of $3 \times 2.5 \times 2.5 \mathrm{~cm}$, non-compressible swelling noted in the posterior $1 / 3 \mathrm{rd}$ of dorsum of tongue (involving midline and right side of tongue). The function of hypoglossal and lingual nerve was spared (Fig. 1).

Pre-operative haematological investigations were normal. USG Neck was normal and showed a normal thyroid gland. T2 - weighted images of MRI showed a $2.7 \times 2.3 \times 2.9 \mathrm{~cm}$ hyper intense, well encapsulated, soft tissue lesion involving midline and right side of tongue. (Fig. 2) The T1 images showed a hyper intense peripheral rim which is compatible with fat and a hypointense centre. (Fig. 3)

Surgical resection was planned. Informed and written consent was obtained. Under general anaesthesia, in-toto surgical resection of encapsulated lesion was done using a midline Glossotomy approach (Fig. 4), without any

1 - Department of ENT, MCV ENT Clinic, Pollachi, Tamil Nadu

2 - Department of ENT, MCV ENT Hospital, Pollachi, Tamil $\mathrm{Nadu}$

Corresponding author:

Dr Sridurga Janarthanan

email: jsdurga2020@gmail.com 


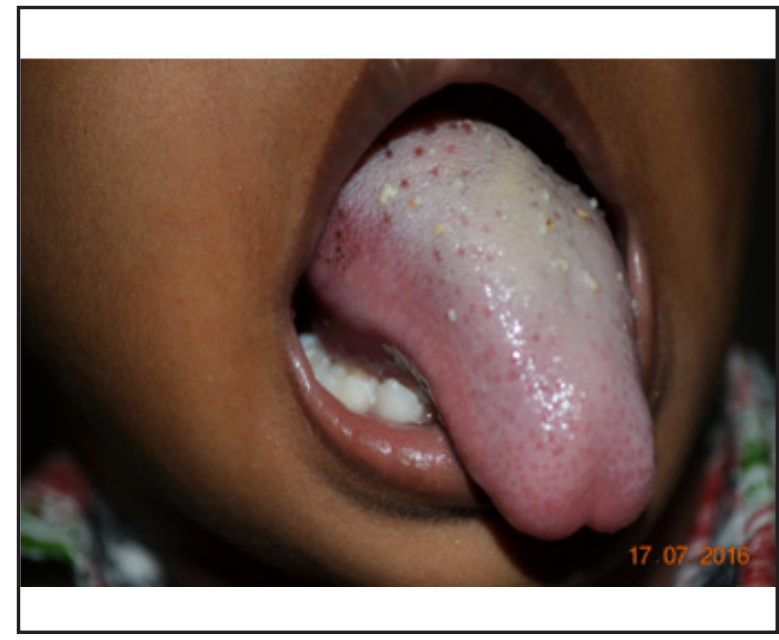

Fig. 1. Pre-op picture showing swelling in posterior aspect of tongue

post-operative morbidity (Fig. 5).

Histopathological examination showed mature adipocytes which were organized in lobules separated by fibrous septae, few immature lipoblasts, myxoid/ myxocollagenous stroma, plexiform capillary network and an intact capsule. (Fig 6)

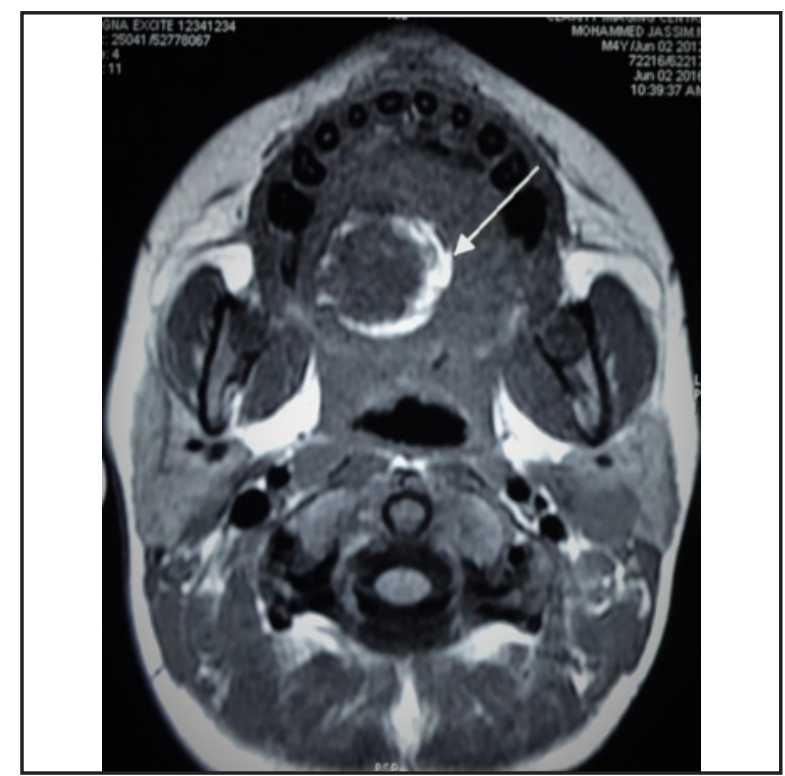

Fig. 3. MRI T1 axial section: Well encapsulated lesion within tongue with rich surrounding capillary network

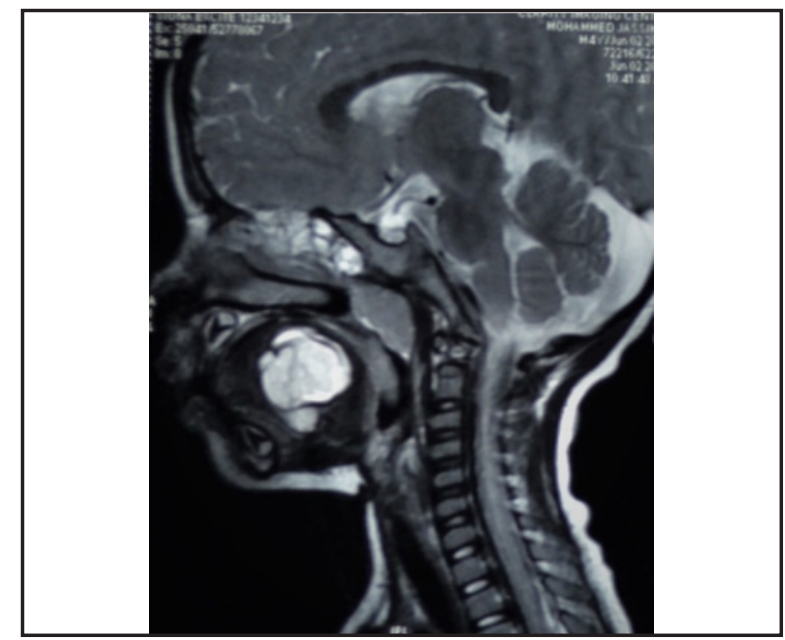

Fig. 2. MRI T2 coronal section: Encapsulated lesion within tongue, with rich vascularity

\section{Discussion}

Lipoblastomas and their multicentric/infiltrative forms, lipoblastomatoses, are rare benign soft-tissue tumours of embryonic lipoid cells. Adipose tumours comprise about $6 \%$ of soft tissue neoplasms of which $94 \%$ are lipomas, $4.7 \%$ are lipoblastomas, and $1.3 \%$ are liposarcomas. ${ }^{1}$ These are known to develop in the first two decades of life.

Lipoblastoma mainly occurs before the age of three

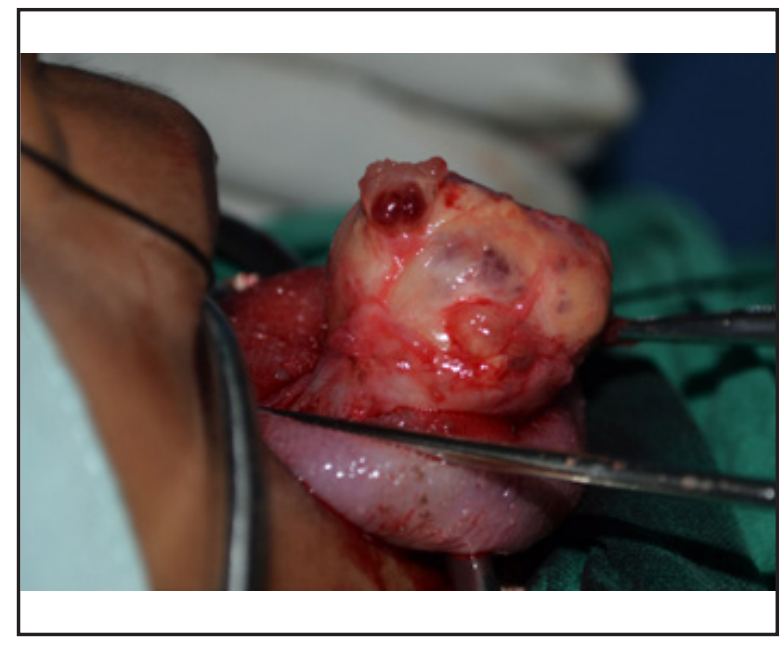

Fig 4. Intra-op. photograph: Excision of encapsulated mass in-toto 


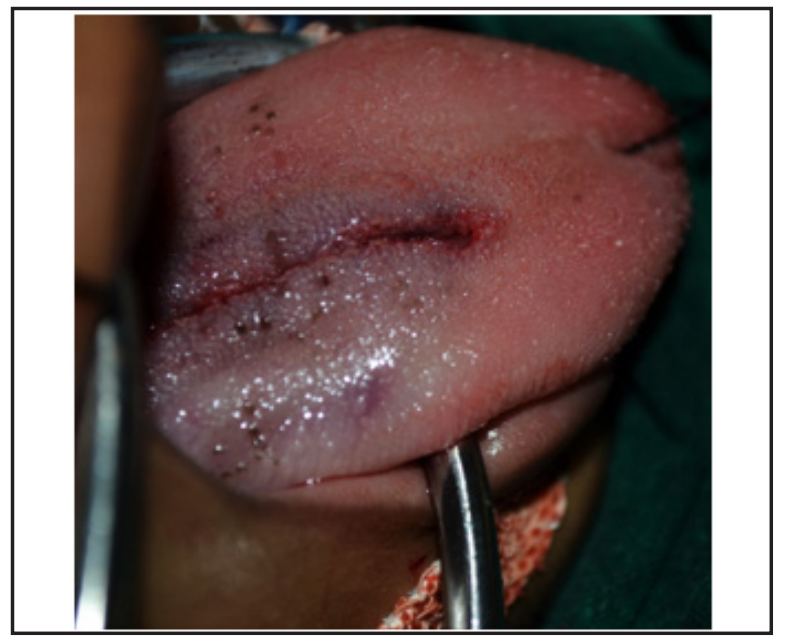

Fig. 5. Appearance post-excision and closure

years and has a male predominance. This tumour is mostly present in the limbs and trunk, with its rare occurrence in the head and neck. ${ }^{2}$ Lipoblastoma is categorized into two types: the circumscribed lipoblastoma (approximately $70 \%$ of cases) - a superficial and encapsulated lesion and diffuse lipoblastomatosis (about 30\% of cases) - a deeply located, poorly circumscribed lesion with infiltrative growth pattern that may affect surrounding muscle structures. ${ }^{3}$

The terms lipoblastoma and lipoblastomatosis were first used by Jaffè 4 and Vellious5, respectively. Less than 200 cases of lipoblastoma and lipoblastomatosis at various locations have been reported in the literature. ${ }^{6}$

The most common presenting symptom is a painless, progressively growing mass which is localized superficially. Other symptoms are related to the location and size or mass effect of the lesion. Airway obstruction and respiratory symptoms have been described in patients with pleural, mediastinal, pulmonary, and lower neck lipoblastomas. Gastrointestinal symptoms, such as emesis, diarrhoea, anorexia and abdominal pain occur in patients with mesenteric or retroperitoneal lipoblastomas. Depending on the location, nerve compression and related symptoms can be present. ${ }^{7,8}$

Head and neck lipoblastoma cases have rarely been reported in literature owing to their low incidence. Calhoun et al. reported the first case of lipoblastoma

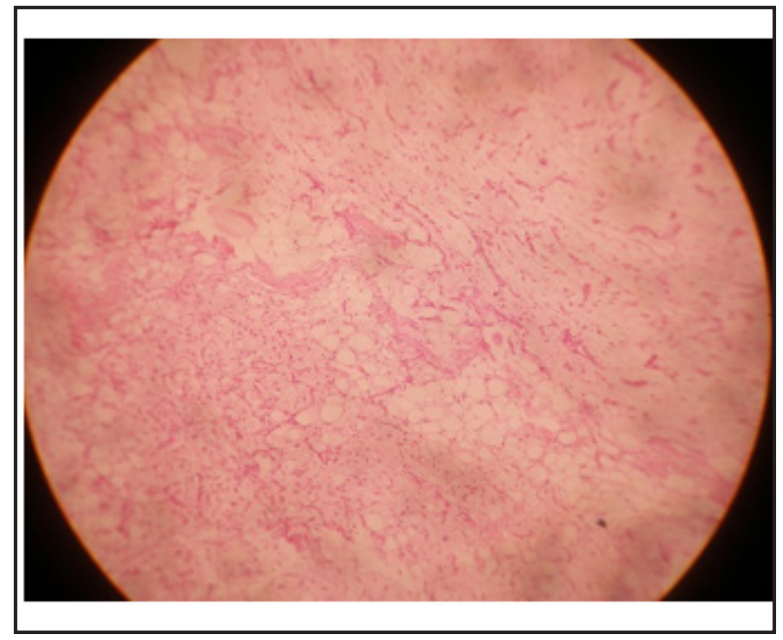

Fig 6. Lipoblastoma: Infiltrating islands of tumour tissue (H\&E, 100X)

in salivary gland which occurred in the parotid gland. ${ }^{9}$ Rasmussen et al. mentioned a case of cervical lipoblastoma causing intermittent airway obstruction. ${ }^{10}$ Farrugia et al. reported another case of lipoblastoma in the neck which had presented with rapidly enlarging mass, mimicking cystic hygroma. ${ }^{11}$ A case of lipoblastoma in parapharyngeal space was reported by DePasquale et al. ${ }^{12}$

On imaging, lipoblastoma appears as a well-defined soft tissue mass, often with lobular appearance and having internal septations. The imaging appearance of lipoblastoma depends on the proportion of fat relative to the amount of myxocollagenous stroma. Fat in lipoblastoma appears as hyperechogenic areas on ultrasonographs, areas of low attenuation on CT images and signal intensity identical to that of subcutaneous adipose tissue. The myxoid components are hypoechoic on ultrasonographs, have low attenuation on CT images (but less hypodense than fat) and on MRI have low signal intensities on T1-weighted images and high signal intensities on T2-weighted images; contrast enhancement of these areas reflects the rich capillary network. . $^{8,13,14}$

Lipoblastoma exhibits a tendency to invade locally. If not excised early, it may enlarge, and infiltrate the various surrounding spaces, present pressure symptoms and may lead to various complications as well. 
Fine needle aspiration cytology is the basic investigation for diagnosis. It can be confirmed by excision biopsy and histopathological examination of the specimen. Histologically, the lesions are composed of immature fat cells (lipoblasts) in varying stages of maturity, mesenchymal cells, a plexiform capillary network, myxoid stroma and mature adipocytes organized in lobules by fibrous septa. There is no nuclear atypia.

If the pathologist is unable to differentiate lipoblastoma from myxoid liposarcoma, a cytogenetic analysis should be done. The typical chromosomal abnormality associated with lipoblastomas is breakpoints in the long arm of chromosome 8 (area 8q11-13), whereas myxoid liposarcomas typically show translocation $\mathrm{t}(12,16)$ (q13;p11) and atypical lipomatous tumour shows amplification of the MDM2/CDK4 genes on $12 \mathrm{q}[7-$ 10]. ${ }^{15-19}$ The age of our patient, the tumour lobulation, its well-circumscribed nature, and the typical histological findings in our case made cytogenic investigations unnecessary. ${ }^{20}$

CT scan or MRI is a must to assess the tumour extent and also to plan surgical approach. Reiseter et al reported that MRI is the most reliable method, with USG and CT having complementary roles. ${ }^{21}$ It is difficult to distinguish lipoblastomas from liposarcomas by imaging studies because of their similar feature of vascularity. However, lipoblastomas usually occur within the first 3 years of life, and diagnosis after the age of 5 years is unusual. In contrary, liposarcomas are extremely rare prior to 5 years of age.

The natural history of lipoblastoma is to evolve into mature lipomas. ${ }^{8,22}$ The treatment used for lipoblastoma and lipoblastomatosis is wide surgical resection. ${ }^{17}$ Recurrence develops in 9 to $25 \%$ of cases and is mostly seen in cases of with infiltrative lipoblastomatosis and incomplete resection. ${ }^{8}$ Metastasis has not been reported to date and the prognosis is good.

\section{Conclusion}

Though lipoblastoma is an uncommon childhood tumour, it should be taken into consideration as a differential diagnosis of head and neck masses. It usually presents as a progressive painless swelling, rarely causing any symptom. Imaging is helpful showing the precise location and extent of the lesion. Although the ratio of fat to myxocollagenous tissue in the tumour is variable, the diagnosis can be suggested in most cases based on the imaging characteristics. Recommended treatment is complete surgical excision and confirmation of diagnosis by histopathological examination.

\section{References}

1. Miller GG, Yanchar NL, Magee JF, Blair GK. Lipob- lastoma and liposarcoma in children: an analysis of 9 cases and a review of the literature. Can J Surg. 1998; 41: 455-8

2. Sakaida M, Shimizu T, Kishioka C, Majima Y. Lipoblastoma of the neck: a case report and literature review. Am J Otolaryngol. 2004; 25: 266-9

3. Papaioannou G, Sebire N, McHugh K. Imaging of the unusual pediatric 'blastomas' Cancer Imaging 2009; 9:1-11

4. Jaffè RH. Recurred lipomatoustumors of the groin: liposarcoma and lipomapseudomyxomatodes. Arch Pathol. 1926; 1:381-7

5. Vellios F, Baez J, Shumacker HB. Lipoblastomatosis: a tumor of fetal fat different from hibernoma. Report of a case, with observations of the embryogenesis of human adipose tissue. Am J Pathol. 1958; 34:1149-59

6. McVay MR, Keller JE, Wagner CW, Jackson RJ, Smith SD. Surgical management of lipoblastoma. J Pediatr Surg. 2006; 41:1067-71

7. Pham N, Poirier B, Fuller S, et al. Pediatric lipoblastoma in the head and neck: a systematic review of 48 reported cases. Int J Pediatr Otorhinolaryngol. 2010; 74:723-8

8. Murphey M, Carroll J, Flemming D, et al. From the archive from AFIP. Benign musculoskeletal lipomatous lesions. Radiographics 2004; 24:1433-66

9. Calhoun KH, Clark WD, Jones JD. Parotid lipoblastoma in an infant. Int J Pediatr Otorhinolaryngol. 1987; 14(1):41-4

10. Rasmussen IS, Kirkegaard J, Kaasbol M. Intermittent airway obstruction in a child caused by a cervical lipoblastoma. Acta Anaesthesiol Scand. 1997; 41(7):945

11. Farrugia MK, Fearne C. Benign lipoblastoma arising in the neck. Pediatr Surg Int. 1998; 13(2-3):213-4

12. DePasquale K, Deschler DG. First report of a lipoblastoma of the parapharyngeal space. Ear Nose Throat J. 2002; 81(8):5648

13. Navarro OM, Laffan EE, Ngan BY. Pediatric soft-tissue tumors and pseudotumors: MRI imaging features with pathologic correlation. Radiographics 2009; 29:887-906

14. Castellote A, Vazquez E, Vera J, et al. Cervicothoracic lesions in infants and children. Radiographics 1999; 19:583-600 
15. Miller GG, Yanchar NL, Magee JF, Blair GK. Tumor karyotype differentiates lipoblastoma from liposarcoma. J Pediatr Surg. 1997; 32: 1771-2

16. de Saint Aubain Somerhausen N, Coindre JM, Debiec-Rychter $\mathrm{M}$, et al. Lipoblastoma in adolescents and young adults: report of six cases with FISH analysis. Histopathology 2008; 52:294-8

17. Hibbard MK, Kozakewich HP, Dal Cin P, et al. PLAG1 fusion oncogenes in lipoblastoma. Cancer Res. 2000;60: 4869-72

18. Tallini G, Akerman M, Dal Cin P, et al. Combined morphologic and karyotypic study of 28 myxoidliposarcomas. Implications for a revised morphologic typing (a report from the CHAMP Group) Am J Surg Pathol. 1996; 20:1047-55

19. Sciot R, De Wever I, Debiec-Rychter M. Lipoblastoma in a 23-year-old male:

20. distinction from atypical lipomatous tumor using cytogenetic and fluorescence in situ hybridization analysis. Virchows Arch. $2003 ; 442: 468-71$

21. Jung S, Chang P, Luo C, Huang C, Lai J, Hsueh C. Lipoblastoma/ lipoblastomatosis: a clinicopathologic study of 16 cases in Taiwan. Pediatr Surg Int. 2005; 21: 809-12

22. Reiseter T, Nordshus T, Borthne A, Roald B, et al. Lipoblastoma MRI appearances of a rare paediatric soft tissue tumour. Pediatr Radiol. 1999; 29(7):542-5. doi: 10.1007/s002470050641

23. Bruyeer E, Lemmerling M, Poorten VV, et al. Paediatric lipoblastoma in the head and neck: three cases and review of literature. Cancer Imaging 2012; 12:484e7. 